
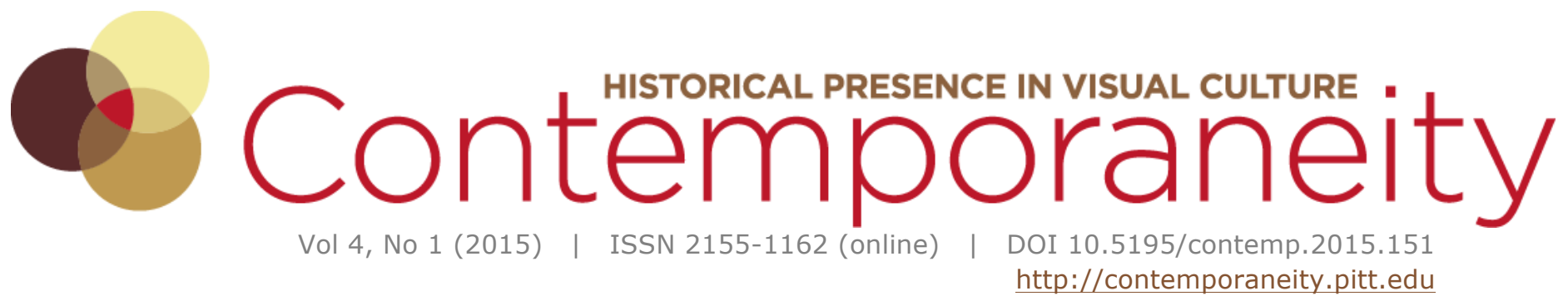

\title{
Curatorial Practice as Production of Visual \& Spatial Knowledge Panel Discussion, October 4, 2014
}

\begin{abstract}
The following is a transcription of a conversation between curators of art, science, and digital data about how their practice creates knowledge in their respective fields. Drawn from Pittsburgh's rich institutional resources, the panelists include Dan Byers, (then) Richard Armstrong Curator of Contemporary Art, Carnegie Museum of Art; Dr. Alison Langmead, Director, Visual Media Workshop, Department of History of Art and Architecture, and Assistant Professor, School of Information Scienes, University of Pittsburgh; Dr. Cynthia Morton, Associate Curator of Botany, Carnegie Museum of Natural History; and Dr. Terry Smith, Andrew W. Mellon Professor of Contemporary Art History and Theory, University of Pittsburgh. Moderated by Nicole Scalissi, PhD candidate, Department of History of Art and Architecture, University of Pittsburgh. Introductions by Colleen O'Reilly, PhD candidate, Department of History of Art and Architecture, University of Pittsburgh. The panel took place as a part of Debating Visual Knowledge, a symposium organized by graduate students in Information Science and History of Art and Architecture at the University of Pittsburgh, October 3-5, 2014. The transcription has been edited for clarity.
\end{abstract}




\title{
Curatorial Practice as Production of Visual \& Spatial Knowledge
}

\author{
Panel Discussion, October 4, 2014
}

Colleen O'Reilly (CR): This panel was conceived and organized by Nicole Scalissi, who is a fourth year PhD student in History of Art and Architecture. Her research focuses on images of staged violence in contemporary art and the expansion and contraction of categories of gender within performative spaces. Nicole carries a Master's degree in Art History from Penn State where she completed her qualifying paper on Andy Warhol's paintings of female wrestlers and the construction of female masculinity.

Our panelists, first, Dan Byers. He is the first Richard Armstrong Curator of Modern and Contemporary Art at the Carnegie Museum of Art and his recent shows include the first U.S. museum exhibition of the Icelandic artist Ragnar Kjartansson and he was the co-curator of the 2013 Carnegie International.

We have Dr. Cynthia Morton, who is an Associate Curator and Head of Section of Botany at the Carnegie Museum of Natural History, ranked as one of the top five Natural History Museums in the U.S. Dr. Morton's research involves the taxonomic relationships using morphological and molecular data of a large tropical group containing many citrus fruits. Dr. Morton also works with the Pennsylvania Department for the Conservation of Natural Resources to document the plant diversity for each county in Western Pennsylvania, to aid in the restoration of natural resources. Dr. Morton holds a PhD from CUNY and the New York Botanical Gardens.

Dr. Alison Langmead holds a joint faculty appointment here at Pitt between the Dietrich School of Arts and Sciences and the School of Information Sciences. She is the principal contact of the DHRX (Digital Humanities Research at Pitt), which represents a transdisciplinary network of scholars who use digital methods to study the ways in which humans interact with their environments, whether social or cultural, natural or human created. Dr. Langmead holds a PhD from Columbia University.

And then we have Dr. Terry Smith, who is the Andrew W. Mellon Professor of Contemporary Art History and Theory here at Pitt. His major research interests include contemporary art of the world, including its institutional and social contexts, the history of multiple modernities and modernisms, and the history and theory of contemporaneity. Dr. Smith is author and editor of many books on modern and contemporary art history and theory including Thinking Contemporary Curating, published by Independent Curators International in 2012.

Nicole Scalissi (NS): Thank you so much, Colleen, for this introduction. Thanks to all of the panelists for accepting my invitation and I want to thank them for their generosity and their spirit of experimentation and collaboration. Since these scholars come from various disciplines, for this panel, I will put them into a conversation on how curating can produce knowledge on both visual and spatial levels.

My plan is to put Dan and Cynthia in conversation with each other, and also ask Terry and Alison to think through questions together, and then hopefully ask questions of each other, about what curating means for us both in general terms and in our own disciplines. Towards the end of the discussion, I would like to invite the audience to participate as well and perhaps pose questions to our panelists.

So first, Cynthia and Dan, to put you in conversation: you have this institution, the Carnegie Museum, in common. I am curious about the relationship between your research and public exhibitions. Cynthia, can you explain the basics of your job, so we get a better sense about 
what it means to be the curator of botany and also what the relationship is between your research and public exhibitions?

Cynthia Morton (CM): My job entails research, getting grants and outreach. That means I have to publish in peer-reviewed journals. I have to pull in grant money, and here at the Natural History museum, your sources are limited. You are asked to get funding from places like NSF (National Science Foundation), and from State Agencies, so it is very different. It is very academic, but in an academic world, I'd probably be able to get funding from other places. Here, it is very limited where you can go. Outreach means that I have an adjunct position as a professor at both Pitt and at CMU (Carnegie Mellon University), and so I teach there, and I also teach a broad range of topics here, from children that come through to board members. I work with a broad range of people from Girl Scouts, libraries, and homeschoolers. You may say, "Oh, isn't that very difficult?" You know, I must admit, sometimes the same lecture I give to a four-year-old, I also give to a forty-year-old. Visually, because I work with morphology and molecules, it's really challenging to get across ideas, and I am trying to use a variety of means when I do that, by talking about it, showing it, and giving students something to touch.

With one activity, we cut out a bunch of ACGTs, that's the code for DNA, and I have them lay out about 35 letters, and then we go to a place called GenBank and look up what they are. They can pull up fish and bacteria, and start thinking across about different concepts. It's tactile, it's something that they can see, and it's great getting them to do something and then figuring out what it means. So that's what my job consists of, which Dan, as a curator may do a little bit differently.

NS: Dan, can you explain your job as a curator at the Carnegie Museum of Art? And also maybe both you and Cynthia can work through this problem of researching for exhibitions for us.

Dan Byers (DB): The research component in my job, in relation to what we talked about, is thinking about contemporary art in relationship to the museum's collection, its programming, its history, and its relationship to other institutions and fields of art history, curatorial practice, and what artists are doing. All that is how I occupy my time but, of course, the decisions about what exhibitions I present here, that research falls through to the exhibition program, so my job consists of both caring for and building the museum's collection of art post-1945.

About half of my time is spent researching acquisitions and in the actual acquisition process. The other half of my time is spent on exhibition-making, working with artists, doing studio visits, travelling, and research. It is interesting, talking about how we get grants. I have to write all of the grants as well but there's a lot of individual donor cultivation and that type of fundraising, so that is also a very present side of what I do.

CM: Speaking of collections, many people are not aware that I am also in charge of collections at the Natural History Museum. We have over half a million plant specimens, which are on dry, 11 by 17 sheets and that's in an herbarium. We have to bring in new specimens and we also have to do something with that data. When I arrived here, one of the big parts was getting everything data-based.

We do a collection here a little bit differently. While Dan actually uses it daily in creating exhibits, here in the Natural History Museum, the only roaming exhibit hall we have is on the upper floor. There's a Hall of Botany and we are trying to bring more stimulation into it. 
There are dioramas in there from the 1940s that are just amazing. The information that you have in there is absolutely fascinating and you can do so much more with that data by looking at it in different ways. For instance, for plants, I always tell people, your air, your food, and your medicine comes from it. All those things can be conveyed though these dioramas. We are trying to generate more knowledge coming out of our halls because we only have one that is basically constantly changing, and when they do bring something in, they are not fabricating it.

DB: It is interesting that the whole idea of visual knowledge here is knowledge related to education. We use our collections of art in many different ways. Still, we try to look at our permanent collection as a living collection, one that is contingent and subjective, and displayed in various ways, depending on either my subjective approach as the curator or from a revisionist approach to art history. But I often wonder in those spaces, especially in our permanent collection galleries, how much of what we're trying to do here is educational? Though the experience of art is education, of course, we double as a place to experience art. That experience can be defined in many ways.

We try to teach people a very basic primer of contemporary art history through exhibition, because, of course, there is very little or no art history in American education. The way that we have approached our permanent collection has to both appeal to and to teach those who know nothing about 1945 to the present in international contemporary art. It also has to be the legitimate curatorial statement or art historical statement, or artist statement about art for those who are coming to the museums to engage in that discourse. So this experience is not necessarily about learning but about engagement or confrontation with art.

NS: Cynthia, education has been one of the key concepts we were talking about earlier when we were discussing your research. Could you discuss a little bit more now about how important that is to you? When you were discussing the static Hall of Botany and about reactivating that through teaching, you had a number of strategies that you were excited to talk about.

CM: Sure, the Hall of Botany. My research deals with Rutaceae, which is citrus.

As research, I collect citrus and I figure out relationships. Citrus is economically important. It's used in medicine. It is used for a variety of things. If you understand the relationship of these things, you can basically use it better. The Hall of Botany has a whole case of citrus, but in the twelve years I have been here, they've never used one of my research articles. I like people to touch things, see things, smell things, and eat things, and I think through all of these things, no matter the age, there is a connection. One time, we were talking about extreme environments with kids. We then acquired some food from that area and asked kids to taste it and to look at the plant. We have to be very careful with our plant specimens because some of them are from the 1800s. We find that we can Xerox nowadays, and we get kids to touch, look at them, and say, "See this is the plant where cinnamon comes from," or, "this is the plant what walnut comes from," to help them make that connection. I would love to see our Hall of Botany bringing in Whole Foods for kids to try stuff, and look at stuff, and have that connection there about where their food came from.

My research has also spanned to look at urban trees. We found out several years ago that most of our trees planted in the urban environment are cloned. Cloning is bad because, if you have everything the same, something like the emerald ash borer comes through and it wipes out all of the trees. Therefore, this isn't something just important to Pittsburgh, this is something important all across the United States. Then, we realized, here's an easy fix. We should give cuttings of these beautiful old trees outside to huge nursery factories out in 
Washington and Oregon and fix the problem. Once again, it's important to get that information across to people, and to kids. Getting that across is one of the ways of being creative with education and there are different methods of doing that.

NS: Many of the ways that you describe getting that information across has been tactile. You want them to do things, smell things, eat things, and touch things. It seems that it is beyond the visual in many ways. I was wondering, Dan, if you had comments about how you engage with the other senses or, if your curatorial practice is exclusively visual. Is it the visual that helps you construct an argument?

DB: The arguments I am making are largely constructed in space visually through comparison, juxtaposition, and through durational accumulation of experience. Those sets of choreography or syntax are definitely the way that I work with art and space.

However, many of the artists that I work with are interested in engaging other senses and that can create interesting tension in a museum environment where we are not hugely receptive to food and other non-traditional materials inside the galleries. It is an interesting tension between the museum's obligation and mission to collect and preserve. The collection is forever, so we create a condition in the museum that is conducive. However, there are also many artists we're bringing in that want to use food, chemicals, oils, and various kinds of things in artworks. Different institutions have different protocol levels for that.

One of the reasons I am a curator is to be able to construct an argument in space and to work with artists in a gallery as the medium for the message and the medium for thinking about art. Compared to essay writing which is also a big part of what I do, I think, art lives very differently within a space.

NS: I've been asking about research as something that you conduct, that you perform, and those results sometimes end up in a public exhibition and sometimes don't. I am also interested in this idea that curation itself is a type of research methodology. Terry, can we see curation as a type of research methodology?

Terry Smith (TS): Absolutely. The main thing I tried to do in Thinking Contemporary Curating was to identify what was specific in contemporary curatorial thinking as distinct from what we might imagine to be relatively typical art historical thinking, or art critical thinking, or theorizing about art. Each one of us on this panel comes from a different disciplinary background, and we have assumptions that are grounded in our disciplinary training. Yet we are also trying to transform our home disciplines for the better, not least through interaction with adjacent ones.

Art critics, theorists and historians have immediate responses to works of art-often to artworks they are seeing in exhibitions or museum installations, that is, in already curated situations. They consider their responses, then articulate them in language that is shared with their readers, the potential viewers of the artworks, those who might attend the exhibition. Meanwhile, the work of the curator has already been done: it is mostly manifest in the exhibition itself, supplemented by written words, in wall texts, catalog statements, and related discussions. But the core work that the curator does, based on the research and thinking that we just heard about, is to create an exhibit.

To exhibit something is to hold it out, as evidence, for inspection, instruction, education, or entertainment. We might also say, speculatively, that an exhibition removes the inhibitions from works of art. An exhibition organizes a selection of artworks in a certain way, as Dan just said, and constructs them in space, as points on a journey through a space or sequences 
of spaces. To curate is to offer a different kind of argument about art than that offered by critic, theorist, or historian. To begin with, it is logically prior to what they do, and usually precedes their ways of making art public. I am fascinated by the nature of the kind of thinking that takes each artwork as a potentially exhibitable object, idea or event. It could be exhibited alongside other ones in a plain, sequential way, or become the key to everything that is arranged around it. These days, non-art objects are frequently thrown into the mix. Alternatively, an exhibition could set up unequal, different, variable dialogues that have beginnings, developments, and ends. To a degree, these options parallel the ways in which art historians or theorists shape and present an argument. But curating operates primarily in terms of potential connections between a number of artworks, each of which is imagined, or prefigured, but the curator as an element within a possible exhibition.

When the exhibition is installed, its meaning emerges within the network of interactions between the actual artworks. There's a constant production of new knowledge in that process, which, again, parallels the new knowledge that art historians discover during their research process. Perhaps we can think of this process as one in which the art historian keep arranging and rearranging a set of images of works by an artist, or groups of artists, as pictures in his or her mind. We check these arrangements against facts we can draw from documents, or statements by the artist, or by comparison with other works, and with known facts about the circumstances in which the work was made. You might say that art historians visit and revisit imagined exhibitions of this kind, ones that exist in a fluid mental space rather than in the constraints of actual rooms. This constraint means that curators have a job that is different in kind. They deal first and last with arrangements of specific artworks, the ones that they can assemble for the occasion. These particular artworks begin talking to each other, and may say unexpected things.

To me, curatorial knowledge can have an impact on art critical, art historical, and art theoretical ways of thinking in showing us how to be more attentive to the interplay between the visual interaction of ideas--abstract ones, quite concrete ones, or even ideas about how historical change happens. Let me give an example of the last. I am just back from presenting a talk about world picturing by contemporary artists at the National Gallery of Art at Ottawa. Afterwards, I had an interesting conversation with the Canadian artist, Geoffrey Farmer. I had admired the work he made for dOCUMENTA (13), at Kassel in 2012, entitled Leaves of Grass. It was an amazing display consisting of photographs cut from Life magazine, from its first issue in the 1930s up until the early 1970s when it ceased publication. He affixed the images to stems of long grass that were mounted in a low base that was lifted to waist height and ran the length of a narrow room. It was a great evocation of the democratic spirit of Walt Whitman's famous poem, and the idea behind Life magazine of seeing the whole world and all who live in it through pictures. Anyway, after my talk, Geoffrey commented on my Powerpoint charts of terms that are widely used to describe how we see the world today, saying 'You arrange your ideas about how the world is now, and what it is like to live today, a lot like I arrange the visual images in my work.' He was thinking about how images and ideas move through historical time, like the wind through grass on an open plain. There is a convergence here between artistic, curatorial, and art historical thinking that is very interesting...

NS: Alison, could you explain a little bit about what your work is, especially since you don't prefer to use the term "digital curation"? Perhaps you could explain what other terms you use, and then also a bit about what your job entails?

AL: Sure. There are two parts of the conversation about how we go about organizing, arranging and making available digital objects, and they are both represented in the work that I do in the Visual Media Workshop. My job has two different components, one of which is to run a traditional digital repository of images, if one can have a "traditional" digital 
repository of images. It has certain criteria for collecting digital images, so I suppose you could think of this collection as something that is a little bit like a collection of specimens, or a permanent collection. But my job here is less to make exhibits of the digital images than to simply make them available, and this is what I wanted to be sure to mention here. I'm trained in the information sciences as well as art history, and this part of my job is information-heavy, and quite specifically focuses on tasks associated with so-called fancy words (which truly aren't that fancy) like metadata and structure standards. These are the things that serve in the digital realm to help people find and organize what they want to work with, and we need these tools precisely because we don't have the physicality of the real world to help us. This is to say, we need to figure out how you find things when you don't have a physical drawer that you can rifle through, or when you don't have walls in a museum that behave in ways that everybody knows about through real-world experience. When you work with a digital space that is very, very flexible-but that isn't infinitely flexible contrary to popular belief-it still doesn't have the same sort of tactile stuff associated with it. You can't smell digital images. You can't use all of your senses in the same way that you can in the physical world.

As for the use of the term, "digital curation," the reason that the use of the phrases data curation and digital curation in the iSchool world have a sort of strange negative connotation for me at the moment is because it co-opts the titles of a profession that is better represented here by my fellow panelists. This type of curation has a broader scope than just the selection, description, and re-presentation of data. That isn't to say that the work of curation doesn't overlap with that of information and data management, or that it doesn't share characteristics, but I don't use the term partially because I have worked with "real" curators in my art history life, and it isn't the same thing as what a digital information manager might do.

The other aspect of my job, however, probably responds better to your question about whether exhibition and curation are related to research, because I also produce academic digital humanities projects. Not that a digital image library isn't a DH project, but its form of argumentation is not the same type of argumentation as the rest of the curatorial panel is presenting. I impress upon my students, some of whom are in the back here, that creating an academic research argument is about knowing your tools and using the one that is most appropriate to your particular needs. The thing that the computer often gives you when you are presenting an academic argument in the digital space is, yes, interactivity, and yes, multimedia events, and affect- but you have that in the real world too. So, don't consider it to be a complete changeover in your approach to research. It is an expansion of your set of tools. Think about what you're actually trying to say. As Terry was just mentioning, you need to consider what it is that you want to convey and then know your toolbox in order to know how to convey it. And in that way, working on research-such as an exhibition project-is the process of learning what you know about what you are doing and then learning what tools you have at your disposal. It is interesting, as [Dan Byers] just said, in the accumulation of experience over the course of a show, which is also something that you can do in a digital space, but you need to construct it differently because there isn't the same sort of longstanding tradition of how you experience necessarily something like this in the digital environment as there is in the physical environment. As Patrick Jagoda [the keynote speaker] was just saying about interactivity and video games, the game can itself manipulate you and show you a new way to experience things, and I suggest that a curator might or might not choose to do the very same thing using their tools and their environments. I consider both of these types of presentation (or publication) a form of research.

TS: The metaphor that comes to my mind is that curating is a sort of software. In this context, it is a kind of a set of practices and protocols, those sort of things. It can operate, perhaps more than art history or criticism, in this character. I see software as a sort of 
interface, and it has certain characteristics relating to what we are talking about, as opposed to the hardware which is the art works and the collections.

AL: It's interesting that you bring up the subject of software in this context, as another thing that I've been thinking a lot about recently is the way that digital machines are actually layers upon layers of these sorts of rearrangements of experience just how you are also talking about it. There are the bells-and-whistles that you see on the front end, but, more or less, if you were to peel back the layers of the modern iPhone, at the bottom, you actually find a computer from the 40s. This object just sort of accreted over time, creating this sort of monster that has, itself, shrunk, but it has basically imploded more than anything else. The whole operation-this hardware-software interface, that we very much still talk about-is still critical even in conversations around computing.

NS: Cynthia, what do you think of this metaphor of curating as a type of software?

CM: As Alison was describing this, I was thinking in my mind, she's talking about evolution.

DB: The idea of curating is very good at generating metaphors. There's so many ways to describe curating. There's a long and ridiculous list, whether you're a custodian, whether you're a producer, whether you're whatever. I think software is a good metaphor to add. Especially being an institutionally affiliated curator, there is an interesting confusion between software and hardware, whether you're talking about this museum, this gallery, this artwork, this history, this collection, this city, these sets of visitors, this sort of obdurate specifics of the space, versus the approach that I bring to playing that space or interacting with it. There's always an interesting back and forth for me between the hardware and the software.

I don't want to confuse these metaphors too much, but I think that's one of the distinctions. You're curating as an untethered act, approaching curating as a way of thought or an approach to art, collection, or ideas versus a job of being a curator at an institution, which offers many different interesting specifics and obstructions and opportunities based on building, staff and city. I find all of these things really enriching, and that's why I choose to situate my practice in a place like this.

AL: I'm running through in my head what I would actually do with the hardware-software metaphor. I'm going to push this somewhere that may or may not be crazy. If I were to make the hardware-software metaphor for curation, I would say that the hardware that curators work with are actually the human beings. They are going to do what they are going to do. You can't shift them. You can nudge them, you can try to get them to do what you want them to do, but the overlay on top that, and what lies over the hardware of the computer, is a series of what I consider to be "hacks." People often talk about hacking computers as something separate from the "real" use of computers, but to me a computer is nothing but hacking-making do with what you have at any given moment. I mean, the inside of a computer can really only do about four or five essential things, but it's the effective combination of those four or five things that make the magic happen-that's hacking. And so in terms of curation, everything that you layer on top of your human hardware-[Dan's] decision of what art to put up, [Cynthia's] decision about which citrus fruit to bring out, [Terry's] decision to make a metaphor in public that actually speaks to art and computing-that is hacking the human hardware system that actually consists of the way that we are socialized to interact with these things. That's where I'd push this metaphor, and the art itself participates in that. 
NS: Alison, I was hoping you could discuss a little bit more about this idea of digital humanities, and I'm curious if you see your work as actually limited to the humanities. How is what you do isolated to the humanities, or could we attach it to other disciplines?

AL: Yes, because I work for two schools, I confront this all the time. I work as a transdisciplinary scholar in the information sciences and, frankly, art history (not "the humanities"). I feel very tied to my home discipline of art history and to doing research and teaching in that discipline. It just so happens that I use a computer to do it. That's the extent to which I am a digital humanist. In the [graduate seminar in the digital humanities] that I am teaching this term, I actually surprised myself on the first day of class with my own polemicism about what $\mathrm{DH}$ is and isn't. Because of this realization, what is really driving my career forward right now is an effort to demystify what it means to "use" computers, and to help people understand better what it is that computers really do and don't do. And, if these people then choose to use digital methods in their own research and teaching then, more power to them, but if they don't, then they made a knowing decision to not use those digital methods, and that is, of course, a completely valid way to move forward. I am not in the DH camp that argues that "all the humanities are the digital humanities," but I do also feel that computers are here, they're integrated in all of our society, and you can't get rid of them. They're on your wrist (although not my wrist), they're in these mics, they're in these lights, they're in that projector, and so everything here could be considered "digital" and "the humanities," but my take on $\mathrm{DH}$ is that the approach is simply a question of how intelligently and proactively you use the digital in your work.

For my own research, I produce digital projects such as Itinera with Drew Armstrong and Decomposing Bodies with Josh Ellenbogen, or even the digital image library. ${ }^{1}$ This is to say that I am studying art history, studying humans and how they interacted with each other (in my case) in the far past. I am also investigating the ways in which the computing infrastructure of the planet can help us reach more people, or reach more specific types of people-digital work doesn't always have to be about "more," the Internet isn't always about "more." It can also be about better targeting specific groups of people. Some of my digital work (especially surrounding Decomposing Bodies) isn't on the Internet and that's where it is going to stay because it isn't appropriate for that work to be so publically accessible due to privacy restrictions or even copyright restrictions.

NS: Terry, I was wondering if you could talk a little bit about these theories of curation you're working on. Can we use what you've observed and what you've theorized in other disciplines? Can we curate botany or non-art objects with what you've been thinking about?

\footnotetext{
1 Itinera is a map-based, interactive, digital resource that overlays and juxtaposes the movements of $18^{\text {th- }}$ and $19^{\text {th }}$-century travelers alongside the objects of their study and their own creative output. Itinera.pitt.edu 
TS: Well, let me tell you a story that connects these ideas. Gregory Pryor is an artist based in Perth, Australia, with a particular interest in botanical illustration. In 2002, he had a fellowship at the Natural History Museum in Vienna. He knew that the Museum held certain specimens that had been collected when Europeans first explored the continent of Terra Australis in the seventeenth and eighteenth centuries. So he looked into the boxes that had the specimens of a plant named Banksia, after Sir Joseph Banks, the scientist who accompanied Captain Cook on his voyages to the Pacific. It's a small desert bush that produces flowers that look like bottlebrushes. They had collected specimens, which, of course, were young, succulent, and green in color, and hadn't flowered. But when Pryor opened these folders, it was obvious that the plants had exploded, turned black and brittle, and scattered their seeds across the archival papers. This is what they do naturally, every year, when it gets very hot. It seems that, during the Second World War, when Vienna was bombed, an explosion close to this building had produced enough heat to generate these plants. Naturally, he made an exhibition out of this phenomenon of time-lapse across differentiated locations.

Contemporary art is so open to experience, and so alert to many different kinds of historical time. Artists love to show these times together, to time travel back and forward in time, between temporalities, and across time. This capacity has been recognized by museums of ethnography and natural history all over the world, so one regularly finds works of contemporary art in all kinds of museums, particularly those that seem to be losing touch with contemporary life.

In the Carnegie International, the French artist Pierre Leguillon created a set of panels and dioramas, one in the main galleries and another in one of the diorama booths in the National History Museum. We were invited to go to a far room in a distant corner of the Natural History Museum. In effect, Dan was drawing a connection between different kinds of archival thinking, researching, and displaying.

It can be amusing to go, say, to the Museum of Archaeology and Anthropology at Cambridge University, and marvel at the persistence of eighteenth-century and nineteenth-century modes of display. The director there, Nicholas Thomas, is very open to contemporary art, and includes a lot of it within the displays. Unfortunately, the architectural setting in such places is so powerful that the contrast between it and the contemporary work has the effect, usually, of underlying the separations and fragilities of cultural continuity rather than reinforcing them. All around the world, we are seeing this phenomenon of museums presenting confused messages about their own temporality, usually for reasons that have more to do with bringing in crowds than expanding their educational outreach. I'm not saying that every museum and every space should become 2014 in its look. But it is dismaying, frankly, to see these different kinds of times jutting up against each other when they're not speaking to each other but are simply abutting each other. I think we need to create platforms, like we're doing right here, to share perspectives, and perhaps, help each other through these dilemmas.

CM: It's really interesting because, in the last several years, this has been at the forefront for me. There's this attitude where people want to spend several million dollars and rip out the Hall of Botany. You don't have to rip it out. You just have to look at it differently. You can actually bring something in to convey. The beauty about botany is that you can go to underprivileged people and students in that group and say, let's walk around Pennsylvania today. "Let's go to a bog," or, "Now, let's go to Lake Erie," and talk about all the cool things that are there, whether we're talking about equisetum (horsetail plant) that you can use to scour your hands and clean with, or talking about the woodpecker in the tree, or about the necessity of dead trees, because that woodpecker needs that tree. We can also talk about why we need an equal balance of things. In the Hall of Botany, we can go to the laurel highlands, a woodland, and even the Florida Everglades. I truly believe we have to find a 
way to make the Hall of Botany more interactive, because it is stagnant there. But, we don't need to rip it out. Each one of those dioramas has plants, animals and insects, and is a whole world. Every single plant in there isn't a dry plant but handmade wax plants. If we remove the dioramas, we will never get that back again. The wax plants are art themselves.

DB: It's interesting to think about the levels of self-awareness an institution can bring to these things, because my attraction to that space is purely through an aesthetic and historical pleasure in this outmoded setting. I always go to the Hall of Botany because it's so quiet, contemplative, and relaxing. When I told Cynthia this, she said, "Oh no, it's supposed to be interactive and engaging." I'll visit a Natural History Museum for the wonder of a specimen. I used to go to the Peabody in Cambridge which was where I grew up going. That was my idea of a natural history museum with wood cases and a nineteenth-century approach to knowledge.

What's interesting about the Carnegie Museum of Art is that we are a museum of museums. We have a Hall of Sculpture, a Hall of Architecture, which are really time capsule places. They display France's architecture in the way that it was displayed in the late nineteenth, early twentieth centuries. We've kept that space essentially as is. But there's been an institutional mediation to talk about how it is a hundred year old display, that's on display as a display of museology. This approach gets complicated. It's between the actual display of knowledge versus a kind of self-aware approach to the history of that knowledge. I think about museum display and the growing field around exhibition history as a way to look at art history. I wonder if in the digital humanities, Alison, you're beginning to historicize your research knowledge or culture through the artifacts, the websites, and the different kinds of interactive things that are being produced. Are you historicizing the way that we're looking at art history or the history of science through exhibition history?

AL: That's a fascinating topic of conversation. A student of mine [Aisling Quigley] and I are currently working on a project that is looking at one of the oldest $\mathrm{DH}$ projects produced at Pitt, Alison Stone's MedArt (http://medart.pitt.edu). The first web crawl of MedArt by the Wayback Machine (https://archive.org/web/), was the first web crawl that the Wayback Machine ever made. This makes MedArt older even than the Wayback Machine. And it happens that we are finding that the technology that underpins MedArt is so basic, and so fundamental to the way that the Internet itself works, that it has helped it hold up pristinely this entire time. Other projects do not fare as well, and we are finding that it is the case that the most easily sustainable $\mathrm{DH}$ projects on the web have been the ones that are the least "fancy."

The fancy digital bells and whistles require that we change, transform, and remediate that technology over time because these types of technologies go obsolete and stop working, which is almost the inverse of the case of [Cynthia's] wax flowers that cannot be put back once they've been forcibly ripped out. With digital projects, we oftentimes have to transform it into a very different state just so that it can persist. It is therefore very difficult to go back and time and look at these exhibitions or projects and see them as they once were, unless their technologies were so fundamental to the Internet that they can stay the same. But, if you go and visit MedArt right now, you will notice that there is a cost for this. The site looks quite dated, a bit like our earlier discussion of the look-and-feel of the Hall of Botany. MedArt uses background tiles (remember them?) and displays an aesthetic that reminds one of the Web was when it was all Animaniacs and William Shatner. So, yes, we are thinking about the history of $\mathrm{DH}$ projects, but we are facing a type of obsolescence that the physical world doesn't give us any helpful analogous, tactile experiences to understand. It ends up being a lot more logical and intellectual, and we have to make decisions, just like archivists do, about which parts of the experience to preserve, because we can't preserve them all. 
NS: So you all have built so much on top of my questions and brought up all these really interesting ways of thinking about your work and each other's work. Are there questions from our audience?

Nicole Coffineau, PhD student in Art History at Pitt: I have a question for Dan. There have been a couple different modes of argument named, such as actually curating objects, making an argument in a digital form, and of course, writing an art historical or critical argument. My question is, how much do you feel like you have to acknowledge the possibility of other modes of argument when you're making your curatorial argument? For example, if you're curating the International, there's a lot written about it in lots of different ways. Do you feel like you have to prepare within your curatorial argument possibly for those other kinds of arguments, or do you block them out?

DB: That's a really good question. I approach them knowing there are contingent modes at work, but I think that everything that is most important to you about that argument or about those artists or about the ideas has to be in the exhibition itself. It has to be present to the viewer and present to someone in that space. Of course, you can't get everything in there, and many of what I consider to be the smartest curatorial moves are lost on a visitor. Or sometimes, they're not aware that they're taking part in an argument or a choreographed situation. There is an interesting relationship between the exhibition and the catalogue, which is a legitimate kind of contingent relationship. When you're looking at an exhibition as a catalogue, you have to understand the back and forth between those things, without excusing yourself to put the most precise arguing in text or in that form. I also think that the knowledge you have of art and working with living artists is always really messy. It's hard to determine, how to separate the knowledge of the artwork from the knowledge of the artist, to the knowledge of the gallery from the knowledge of what your studio assistant did to make this work, to the knowledge of how they think about their artwork situated among the artworks in the exhibition. I've realized in the last few years that the simpler the argument in the gallery space, the better, because then you can use simpler tools like juxtaposition and gallery lighting to affect and become a communicative medium. As much as exhibitions are a way to produce knowledge and art history, it wasn't until I worked in the International that I realized that it could be a communicative thing, that someone could speak through it in a way, and people could understand, and come out the other side not totally garbled.

NS: Cynthia, your title as curator: is that an idea you had chosen before or was that something chosen by the museum? Do you use this term to describe your position?

CM: Natural history curation is not just looking at your specimens but creating research for publication, so I think it's a different form. It's similar to being tenured. I think with each one of us, we all have a very different angle that we take on our profession, our careers, even between art and the natural history. When we talk about curation, I don't think that there's one solid definition. Each runs a little bit differently. My job as a curator fills these different holes and that's how other natural histories fulfill it too. I think that the goal of doing exhibits is downplayed because we don't have that kind of rolling exhibition space. I think of myself as a curator, but it's a different definition. 
TS: For me, the fundamental dynamic in an art museum is the friction between the collection and the temporary exhibition space. In a traditional museum, the temporary space was, often, an experiment for how to reinstall at least one of the rooms in the main collection.

Today, however, temporary exhibitions have become much more varied in type and kind, to such an extent that it's mainly art which originates outside of the museum, rather than art destined for the museum, that is entering the museum, albeit on a temporary basis. Cynthia, could I ask you what prevents the Museum of Natural History from seeing itself as a place that has great permanent art, but also temporary exhibits?

CM: There are very few spaces.

TS: Is it all in the numbers? Do people just like to see the same thing when they go to a natural history museum? Because when it comes to art, the assumption is that most visitors like a mix of familiar and unfamiliar things, but repeat visitors expect reasonably constant change.

CM: Well I think that there's a dual edge here. In Pittsburgh, people do like to come back and see the same thing. But I think that it's going to have to change. Is it by pulling things out and rebuilding things? That's really costly. This particular community is not going to be able to withstand that kind of cost. We have to be creative, and find different ways to get information across. The main people that come in to the Natural History Museum are children and families. We can't just keep it for adults. We have to diversify here. We have small kids coming in and we have to accommodate that. But we can also empower the adults with information so that they can convey it to children. We don't have to rip out the dioramas, but we do have to make it in a way so that people want to come in. But we have to accommodate our audience.

AL: If I might, I'd like to comment about the remediation of arguments, and talk about how we change arguments through different ways of doing. I was struck when Dan was talking about his work, because when you produce a relational database model, it's a lot more like his presentation of curation. You are reconfiguring things in your head and distributing them across "rooms," for lack of a better word, that are notional spaces in the computer's memory that can be easily accessed.

DB: Terry, I want to go back to your question of communication. I've done exhibitions that have gotten both positive and negative reviews, but it wasn't until a lot of the more substantial long-form reviews of the International came out that the critics understood, what I describe as an affective mood of the exhibition. This is something that, as curators, we had only begun to articulate amongst ourselves, but it was picked up in the way and the tone that people wrote. I think that exhibitions can teach people about art history. You can teach people about artists, about the world. The International is special as a way to deal with the world through artworks. What I experienced as a really communicative act or mode was what you would expect from a poem.

It has knowledge in it that is really about conveying how to see the world through feeling. People picked up on the fact that there was engagement with different ways of pleasure, and play, but also the political valiances that are important to us, in our selection and combination of artists and artworks. These things were not explicitly drawn attention to in labels or any traditional modes of communicating information. I'm still trying to figure out 
how we did that, and I'd like to do it again. That is something beyond knowledge and more interactive.

TS: In the international art world, there's a huge, almost impossible demand that every biennial, and now there are 150 of them, should stand out from every other one. The strictest requirement as to how to do that is to invent a variation not so much in what you make the show about, or where it is, or who the artists are, but in how you present the exhibition. Curators now, all around the world, want to see some innovation in exhibitionary form itself. Otherwise, they believe, all the exhibitions remain the same.

I think that you, Daniel Baumann and Tina Kukielski responded to that demand, to a degree-with the play element, and the loans from the Library at Braddock, for example. But it was not your main motivation. No one thing stands out as the key factor in shaping the most recent International. Rather, it was the combination of all of the things you just mentioned which produced the affect that the critics picked up on so astutely. To me, the exhibition profiled a certain mode of being in the world: I would characterize it as tentative yet open, care-filled yet determined, moderately ambitious, watchful yet positive. The exhibition itself, as it came together, produced and generated this affect--more than, as you attest, the fully articulated intentions of the curators. The outcome was, I think, a very important moment in the history of exhibitions in this city. 
(cc) $\mathrm{EY}$

New articles in this journal are licensed under a Creative Commons Attribution 4.0 United States License.

\section{ULIS D-Sonk}

